\title{
Seismicity characteristics of the 2011 M9.0 Tohoku earthquake near the East Coast of Honshu in Japan
}

\author{
XUE Yan ${ }^{1,2^{*}}$, LIU Jie ${ }^{2}$, YU HuaiZhong ${ }^{2} \&$ LIU ShuangQing ${ }^{3}$ \\ ${ }^{1}$ Institute of Geophysics, China Earthquake Administration, Beijing 100081, China; \\ ${ }^{2}$ China Earthquake Networks Center, Beijing 100045, China; \\ ${ }^{3}$ Earthquake Administration of Tianjin Municipality, Tianjin 300201, China
}

Received August 17, 2011; accepted November 7, 2011; published online December 2, 2011

\begin{abstract}
The spatiotemporal evolution of the M9.0 Tohoku earthquake sequence off the East Coast of Honshu in Japan on March 11, 2011 and precursive seismic activity near the Japan Trench show that the earthquake sequence has foreshock-main shock-aftershock characteristics. Its foreshock sequence is characterized by a concentrated spatial distribution, low b value and the same focal mechanisms. Half an hour after the main shock, the two greatest aftershocks, with magnitudes of $M 7.9$ and $M 7.7$, occurred, followed by a rapid reduction in the strength of events. The aftershock activity was enhanced roughly two weeks and one month after the main event. This great earthquake ruptured bilaterally. Five hours after the main shock, the aftershock zone extended over a range that was $500 \mathrm{~km}$ in length and $300 \mathrm{~km}$ in width. A day later, the long axis of the aftershock area had expanded to about $600 \mathrm{~km}$. Nine years prior to the 2011 earthquake, the seismicity in the location of the seismic source for this event enhanced significantly, with the extent of this area of enhanced seismicity being roughly equivalent to the aftershock zone.
\end{abstract}

foreshock sequence, aftershock activity, accelerating moment release (AMR)

Citation: Xue Y, Liu J, Yu H Z, et al. Seismicity characteristics of the 2011 M9.0 Tohoku earthquake near the East Coast of Honshu in Japan. Chin Sci Bull, 2012, 57: 886-893, doi: 10.1007/s11434-011-4885-1

According to the China Earthquake Networks Center (CENC), the M9.0 Tohoku earthquake occurred near the east coast of Honshu in Japan (longitude $142.6^{\circ} \mathrm{E}$, latitude $38.1^{\circ} \mathrm{N}$, focal depth $20 \mathrm{~km}$ ) at 13:46 on March 11, 2011 (Beijing time) (www.ceic.ac.cn). The earthquake triggered a strong tsuna$\mathrm{mi}$, and by April 12 the number of missing and deceased reached 27475 (www.sina.com.cn).

The global earthquake catalog of the U.S. National Earthquake Information Center (NEIC) reports the occurrence of a $M 7.3$ earthquake and 22 shocks with $M \geqslant 5$ in the region of the M9.0 earthquake during the two days (March 9-11) prior to the main $M 9.0$ earthquake. The $M 7.3$ event was only $46 \mathrm{~km}$ away from the epicenter of the $M 9.0$ main shock (http://earthquake.usgs.gov/). In retrospect, these events can be classified as foreshocks in the real sense. The

*Corresponding author (email: xueyan5619@seis.ac.cn) sequence also has had a great number of aftershocks, including three with $M \geqslant 7.0$ within one month after the main earthquake. Therefore, the great earthquake sequence can be characterized as a foreshock-main shock-aftershock type.

Of all of the short-term and imminent precursors, foreshocks are recognized as one of the most effective indicators of earthquake prediction [1]. The contribution of foreshocks is obvious among all the effective short-term and imminent precursors in China, such as the M7.3 Haicheng event in 1975 and the M5.6 Xiuyan earthquake in 1999. However, the effective recognition of foreshocks is difficult. The 1996 Xingtai earthquake in China, led to an increased interest in earthquake sequences [2,3]. Chen [4] and Chen et al. [5] found foreshocks to be concentrated in space and with focal mechanisms that are relatively similar; however, aftershocks were found to be more distributed in space and differed widely in their mechanisms. They also proposed 
that the consistency of the source parameters can indicate whether a sequence is a type of foreshock sequence or a normal main shock-aftershock sequence. Ni et al. [6] studied the temporal and spatial sequence distribution and waveform characteristics of the M4.7 earthquake occurring about $2 \mathrm{~h}$ before the M7.1 Yushu shock on April 14, 2010 in Qinghai at a distance of only $2 \mathrm{~km}$ from the epicenter of the main earthquake. They suggest that the M4.7 sequence is in line with the theory proposed by Chen [4], i.e. that it is a typical foreshock sequence. In addition, statistical methods based on the $b$ value have been used to identify foreshock sequences [7]. In recent years, a number of foreshock investigations have been conducted based on high-precision locations of earthquake sequences. These studies have systematically analyzed the temporal and spatial evolution of foreshock-main shock-aftershock sequences, and provided models to explain the relationship between foreshocks and a main event [8]. Previous foreshock research mainly involved the statistical characteristics of moderate-strong earthquake sequences [9]. Examinations of earthquakes with $M \geqslant 8$ earthquakes were uncommon, and in particular, the study of earthquake sequences with a foreshock of $M \geqslant 7.0$ was rare.

Many studies have been made of the great earthquakes [10-12]. Mogi pointed out that 10 to 20 years before great earthquakes, seismic activity obviously strengthened and a doughnut-shape distribution of earthquakes often formed around the source regions [11]. Mei et al. [12] analyzed the precursive seismicity for 16 great earthquakes on the Chinese mainland and adjacent regions. They noted enhanced seismic activity of moderate earthquakes in the vicinity of the source regions has certain universal characteristics over a long-term preparation stage leading to a main shock earthquake.

In this study, we have used the global catalog, beginning in 1973, from the United States National Earthquake Information Center (NEIC; http://earthquake.usgs.gov/) to obtain data for an analysis of the characteristics of the spatiotemporal evolution of the M9.0 Tohoku great earthquake sequence and, in particular, the features of seismic activity near the Japan Trench before the large event. Through analysis of the Gutenberg-Richter (G-R) relationship, the records of $M \geqslant 5$ earthquakes near the Japan Trench are considered to be basically complete. Taking into account the agency bias in earthquake locations, this work has used both the Japan Meteorological Agency catalog (JMA; http:// www.jma.go.jp/jma/index.html) and NEIC catalog for comparative analysis of the foreshock sequence and the $b$-value for the earthquake sequence. In addition, we make use of part of the global catalog of $M_{\mathrm{W}} \geqslant 7.0$ earthquakes since 1900 in the discussion (which mainly comes from the global catalog from 1900 to 1999, revised by Engdahl et al. [13], and the catalogue from Harvard University after 2000 (http://www.seismology.harvard.edu/)), in which the rec- ord of $M \geqslant 7.0$ earthquakes is complete [13].

\section{Characteristics of the evolution of the M9.0 Tohoku earthquake sequence}

\subsection{Spatiotemporal evolution of foreshocks and first three days of aftershocks}

At 02:45 UTC on March 9, 2011, a M7.3 earthquake was the first event to occur in the great earthquake sequence. By the time of the occurrence of the main shock at $05: 46$ on March 11, $23 M \geqslant 5.0$ foreshocks had occurred, of which two were $M \geqslant 6.0$. Viewed temporally (Figure 1(a)), the foreshock sequence can be divided into three active periods: from 02:00 to 11:00 on March 9 (Figure 1(c), hollow circles), from 18:00 to 23:00 on March 9 (Figure 1(c), solid circles) and from 08:00 to 16:00 on March 10 (Figure 1(c), the triangles). During the first period, all $15 M \geqslant 5$ earthquakes, including one $M 6.0$ shock, occurred northeast of the $M 7.3$ earthquake. In the second period, four $M \geqslant 5$ earthquakes occurred, including two to the northeast of the $M 7.3$ event, and M6.0 and M5.2 events successively to the southwest. The main $M 9.0$ shock took place to the west of the M6.0 earthquake, but its source depth was $10 \mathrm{~km}$ deeper than that of the M6.0 earthquake. In the third phase, all four M5 earthquakes occurred northeast of the M7.3 event (Figure 1(c), triangles). Before the main event, the foreshock sequence was quiescent for $13 \mathrm{~h}$, the most prominent quiescence for the entire foreshock sequence. Note that some previous studies of foreshocks have shown that the closer to the main shock, the more frequent the earthquakes are, but a short calm period would appear before the main shock $[2,14,15]$. In contrast, the calm phenomenon before this main shock was prominent; however, the earthquakes were not frequent. Whether this was affected by the minimum magnitude needs further study.

The spatial distribution of the foreshock sequence is concentrated, with the epicenters concentrated in a range of 40-50 km (Figure 1(b),(e),(f)). From the point of view of depth, the initial rupture point was $30 \mathrm{~km}$ deep (the focal depth of the $M 7.3$ was $32 \mathrm{~km}$ ), then subsequent earthquakes generally occurred at more shallow depths. The focal depths of the foreshock sequence mainly are distributed over the range of 10-40 km (Figure 1(i)).

After the main event, the aftershock zone rapidly extended bilaterally to the north and south, with a greater distribution to the south. Twenty-eight minutes after the main earthquake, the greatest aftershock, with $M 7.9$, occurred about $260 \mathrm{~km}$ to the south of the main shock (06:15). Ten minutes later, the second greatest aftershock, with $M 7.7$, occurred about $200 \mathrm{~km}$ away from the main shock in the east of the trench $(06: 25)$. Five hours later, the NNEdirected aftershock zone was well formed, about $500 \mathrm{~km}$ long and $300 \mathrm{~km}$ wide. Eighteen hours after the main shock (i.e. by 24:00 on March 11), 120 aftershocks of $M \geqslant 5.0$ had 

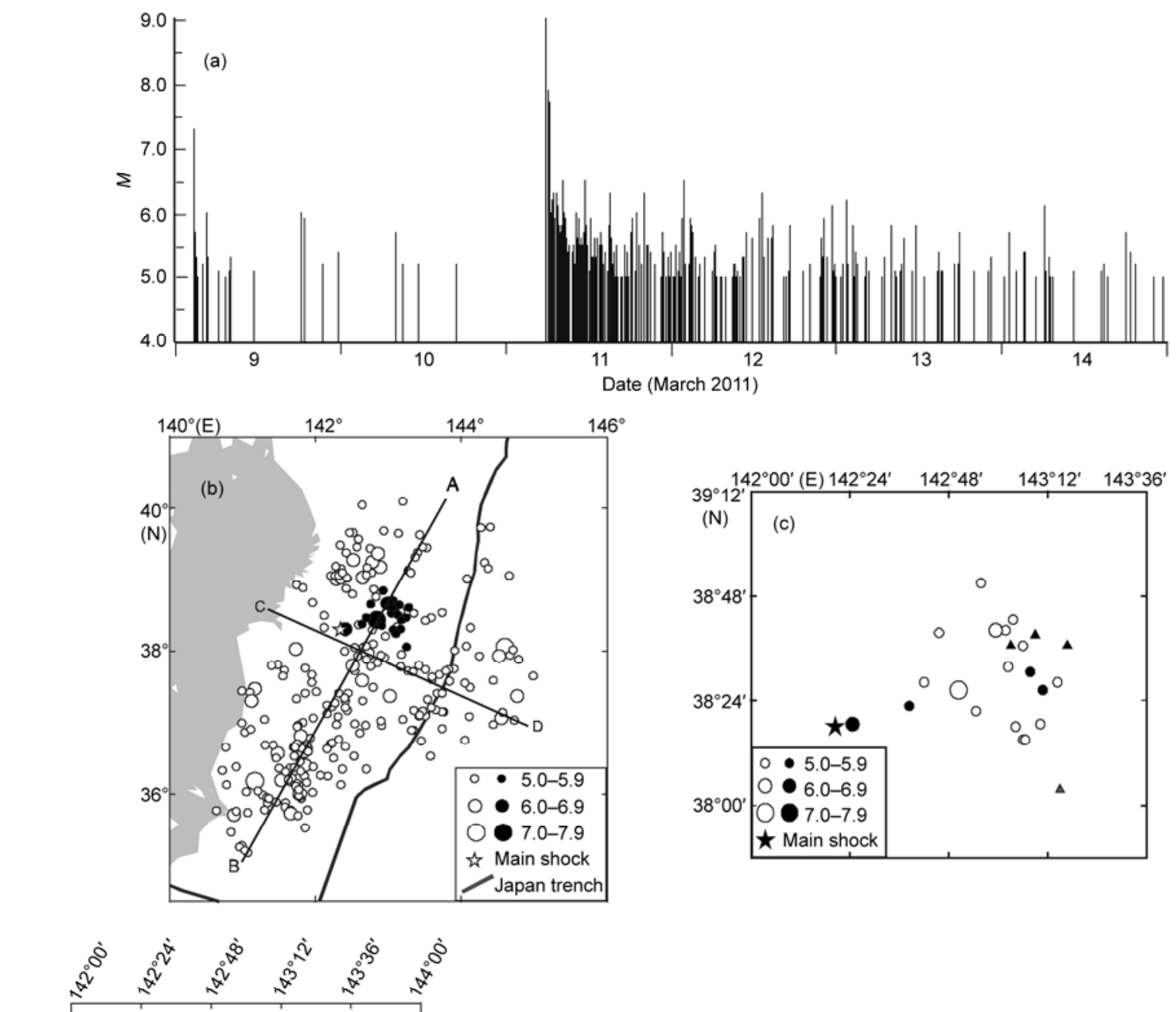

(d)
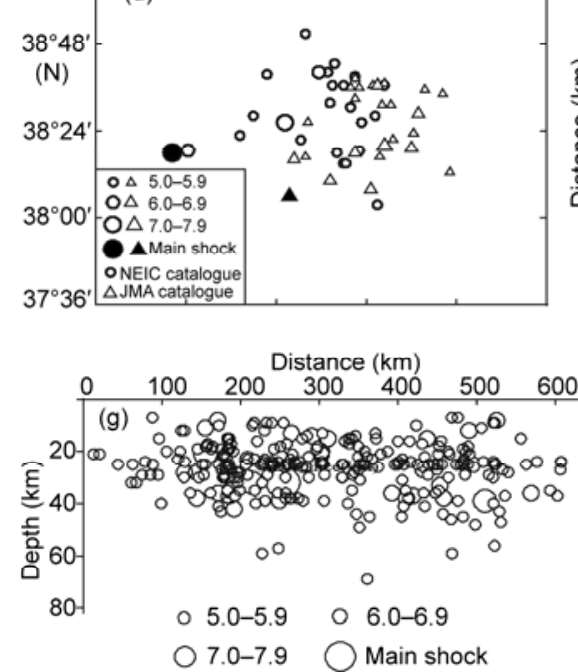

$05.0-5.9 \quad 06.0-6.9 \bigcirc 7.0-7.9 \bigcirc M 9.0$
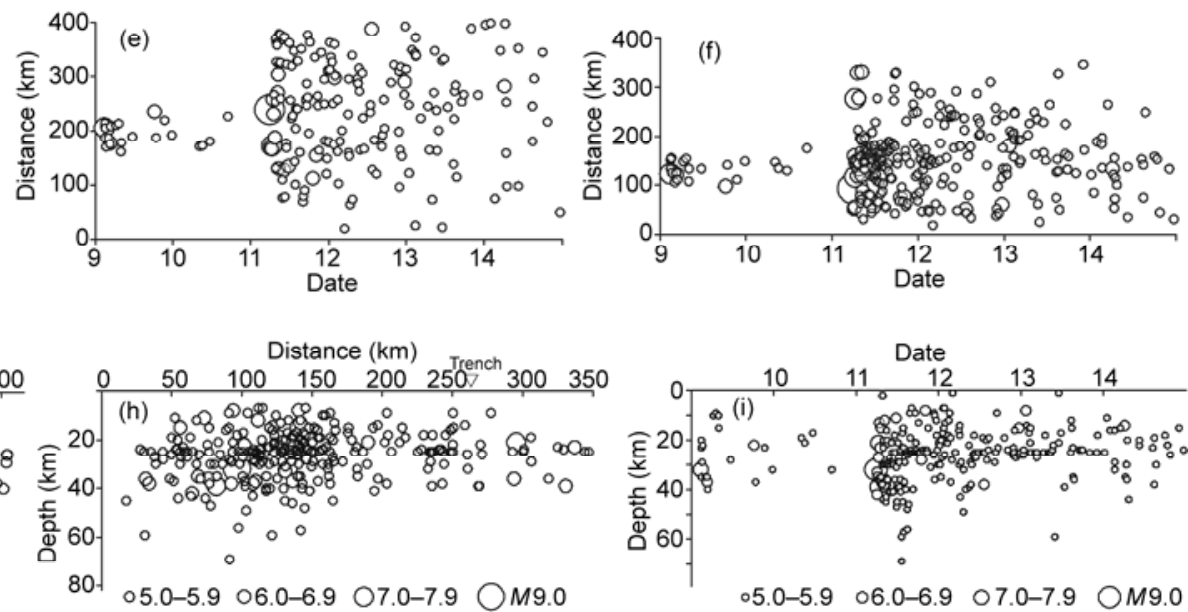

$05.0-5.9 \quad 06.0-6.9 \quad 07.0-7.9 \quad O M 9.0$

Figure 1 Spatial and temporal activity of the earthquake sequences $(M \geqslant 5.0,2011-03-09-2011-03-14)$. (a) $M-t$ chart; (b) epicenter distribution (solid circles for the foreshocks, hollow circles for aftershocks, five-pointed star for the main shock); (c) foreshocks distribution (hollow circles, solid circles and triangles respectively stand for earthquakes occurring from 02:00 to 11:00 am on March 9, from 18:00 to 23:00 on March 9 and from 08:00 to 16:00 on March 10; five-pointed star represents the main shock); (d) epicenter distribution of foreshock sequences from NEIC catalog and the JMA catalog (circles represents the NEIC catalog, triangles for the JMA catalog, hollow circles and triangles for foreshock sequences, solid circle and triangle represent the main shock); (e) epicenter migration map in $\mathrm{AB}$ direction (i.e. projecting the epicenter of the earthquake on the line $\mathrm{AB}$ and calculating the change of earthquake projection distance from point $\mathrm{A}$ over time); (f) epicenter migration map in $\mathrm{CD}$ direction (i.e. projecting the epicenter of the earthquake on the line $\mathrm{CD}$, and calculating the change of earthquake projection distance from point $\mathrm{C}$ over time); (g) focal depth distribution in profile $\mathrm{AB}$; (h) focal depth distribution in profile $\mathrm{CD}$; (i) focal depths varying with time. 
occurred, including 21 earthquakes with $M \geqslant 6.0$ and two $M$ $\geqslant 7.0$ events. Compared to the five hours after the main shock, there was no significant change in the size of the aftershock area. After March 12, there was a slight expansion of the long axis of the aftershock area to a length of about $600 \mathrm{~km}$, with the width unchanged (Figure 1(e),(f)).

From the focal depth profile, we see that along the ocean trench, the distribution of aftershock depths changed little, mainly concentrated to $0-40 \mathrm{~km}$ (Figure $1(\mathrm{~g})$ ). The main aftershock zone was located in the western part of the trench, some aftershocks also occurred in the eastern part of the trench, including the second greatest aftershock of $M 7.7$ and four aftershocks with magnitudes 6.1-6.4. These five earthquakes with $M \geqslant 6.0$ all occurred within the first $2.5 \mathrm{~h}$ after the main shock. In addition, compared with the western side of the trench, the focal depths of aftershocks in the eastern part of the trench were shallow, concentrated in 0-40 km, but there were some earthquakes deeper than $40 \mathrm{~km}$ (Figure 1(h)).

From the time of the main shock until 15:00 on March 12, most of the aftershocks were concentrated in the $0-50 \mathrm{~km}$ depth range, and some were in the 50-70 km range. Subsequently, few aftershocks had hypocenters below $40 \mathrm{~km}$, and they were concentrated mainly in the $0-40 \mathrm{~km}$ range (Figure 1(i)).

In view of some systematic bias in earthquake locations, this paper comparatively analyzed the NEIC and JMA catalogs. The results show that the magnitudes determined from the JMA catalog are generally higher, and the epicenters shift slightly to the east. However, the use of the JMA cata$\log$ in this research has not affected the results obtained using the NEIC catalog. From Figure 1(d), the epicenters determined by the JMA catalog on the whole are more to the east than those from the NEIC catalog. The epicenter of the main shock determined by the two catalogs has a discrepancy of about $50 \mathrm{~km}$. The JMA positioned foreshocks provided a more concentrated spatial distribution, and the main shock was located to the southwestern end of the foreshock sequences.

\subsection{Spatiotemporal evolution of the earthquake sequence in the month after the main shock}

Aftershock activity in the month after the main event showed obvious fluctuations. The $M \geqslant 6.0$ aftershocks can be divided into three periods: March 11 to 17, March 22 to April 1 and April 7 to 12 (Figure 2(a)). During the first three days of the first stage (March 11-13), there were 27 aftershocks with $M \geqslant 6.0$, including two $M \geqslant 7.0$ earthquakes, and these events were distributed across the entire aftershock zone. Four aftershocks with $M \geqslant 6.0$ occurred from March 14 to 17, the greatest being M6.1, moving from the central part to the northern part of the aftershock area. The activity of $M \geqslant 6.0$ aftershocks then calmed and became quiet for four days, before the second active phase began. During the second period, there were eight aftershocks with $M \geqslant 6.0$, the greatest one being $M 6.4$, concentrated in the south-central part of aftershock zone, close to the epicenter of the main shock. Subsequently, the activity of $M \geqslant 6.0$ earthquakes calmed again, this time for $6 \mathrm{~d}$, until a $M 7.1$ aftershock occurred at 14:00 on April 7 about $60 \mathrm{~km}$ west of the epicenter of the main shock. This marked the start of the third active phase. By April 12, four $M \geqslant 6.0$ aftershocks had occurred, with the seismicity migrating to the south. The M7.1 event occurring on April 7 was the strongest aftershock since March 12. Compared with the first two $M \geqslant 7.0$ aftershocks, its epicenter was the closest to that of the main shock (Figure 2(b)).

\subsection{Parameter calculation for the earthquake sequence}

The G-R relationship, $\lg N(M)=a-b M$, as proposed by Gutenberg and Richter [16], is a statistical description of earthquake intensity and frequency distribution, where $N$ is the number of earthquakes with magnitude $M$ and $a$ and $b$ are statistical factors, respectively reflecting the level of seismic activity and the intensity distribution. Studies of Chinese mainland earthquake sequences [9] show that, for the foreshock-main shock-aftershock type earthquake sequence, aftershocks and foreshocks have obvious differences in $b$ value. Figure 3 shows the G-R curves calculated using the NEIC catalog for the foreshock sequence and first three days of aftershocks (March 11-13) and in the first month (March 11 to April 12) after the M9.0 main shock. As shown in the figure, the $b$ values are $0.825,1.111$ and 1.115 for the foreshocks, the three-day aftershock record and the one-month aftershock record, respectively. Clearly, the $b$ value for the foreshocks is significantly lower than that of the aftershocks. This is consistent with previous research $[9,17]$.

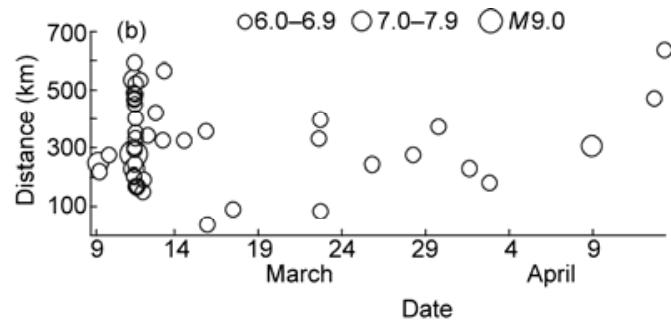

Figure $2 M-t$ chart (a) for the earthquake sequence and $D$ - $t$ diagram (b) of earthquakes with $M \geqslant 6.0$ along profile AB. 
We also made similar calculations using the JMA catalog, and the results are shown in Figure 4. In the figure, the $b$ value is 0.616 for foreshocks, 0.886 for the three-day aftershock record and 0.907 for the one-month aftershock record. In contrast with Figure 3, the overall value of $b$ calculated from the JMA catalog is lower than that from the NEIC catalog. This is because the magnitudes determined by JMA are slightly higher than those by NEIC, except for the main shock and the greatest foreshock. Therefore, this difference is caused by the system bias in the magnitude measurement. Nevertheless, Figure 4 clearly shows that the $b$ value for the foreshock sequence is significantly lower than that of the aftershock sequence.

Based on the Omori aftershock attenuation law [18,19], Liu [20] proposed a method for calculating the $h$ value, the earthquake frequency attenuation coefficient, to determine the sequence type for earthquake prediction studies involving foreshocks. When $h \leqslant 1.0$, the sequence is a foreshock sequence. When $h>1$, the sequence is generally an aftershock sequence, and the occurrence of subsequent greater earthquake is unlikely. Based on calculations for the Toho$\mathrm{ku}$ sequence, the $h$ value is 1.9 for the foreshocks and 1.41 and 1.27, respectively, for the three-day and one-month aftershock sequences. Thus, according to the value of $h$, we cannot identify the foreshock sequence in this case.

Focal mechanism solutions of foreshocks and three days of aftershocks after the main shock (March 11-13) were obtained from Harvard University (http://www.seismology.
Harvard.edu/). They show that the faulting mechanisms, including the strike, dip and the slip directions of the fault planes, are consistent for the foreshocks and main event. In contrast, the focal mechanism solutions for the three-day aftershock sequence are chaotic, with both thrust faulting and normal faulting. Furthermore, the strikes and dips of the fault planes are quite different (Figure 5). This is in line with the theory that the consistency of source parameters can be taken as a precursive indicator in forecasting an earthquake sequence [4].

\section{Enhancement of strong earthquake activity before the great M9.0 Tohoku earthquake}

The great $M 9.0$ earthquake occurred in the Japan Trench, at the intersection of the Pacific, Eurasian, North American and Philippine plates. At the latitude of this earthquake, the Pacific Plate moves approximately westward with respect to the North American Plate at a rate of $83 \mathrm{~mm} / \mathrm{a}$, and begins its westward thrust beneath Japan at the Japan Trench. The Japan Trench region (Figure 6(a), the quadrilateral region enclosed by dashed lines) has experienced strong seismic activity. Since 1900, there have been 69 earthquakes with $M \geqslant 7.0$, including three with $M \geqslant 8.0$, and the large $M 9.0$ event, which is the strongest ever recorded in this region. The $M$ - $t$ chart (Figure 6(b)) shows that there were two active periods, 1900-1939 and 1959-2011, with an average
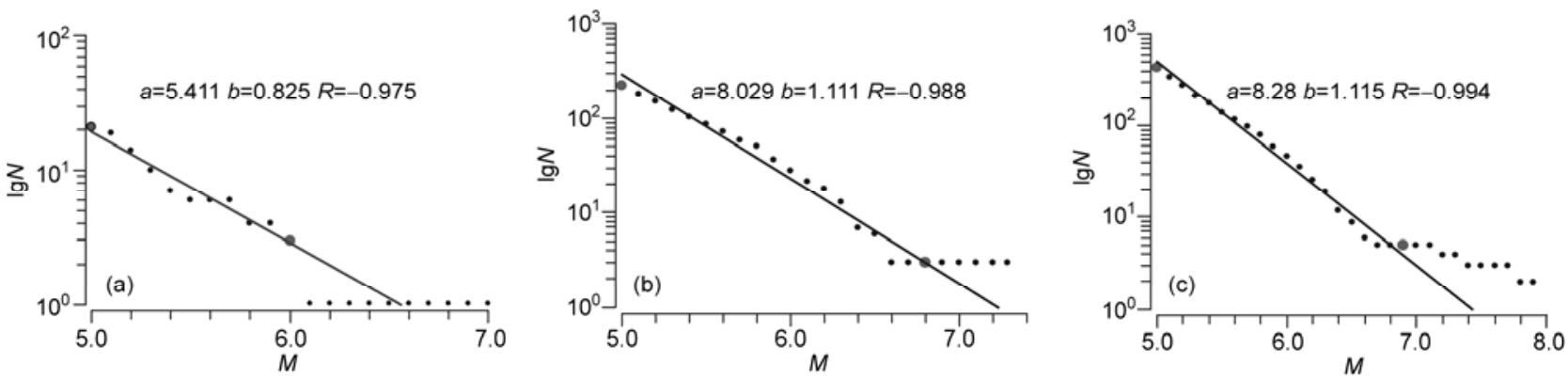

Figure 3 G-R relationships for the earthquake sequences. NEIC catalog: (a) for the foreshock sequence; (b) for aftershocks in the three days after the main shock; (c) for aftershocks in the month after the main shock; $R$ is the correlation coefficient.
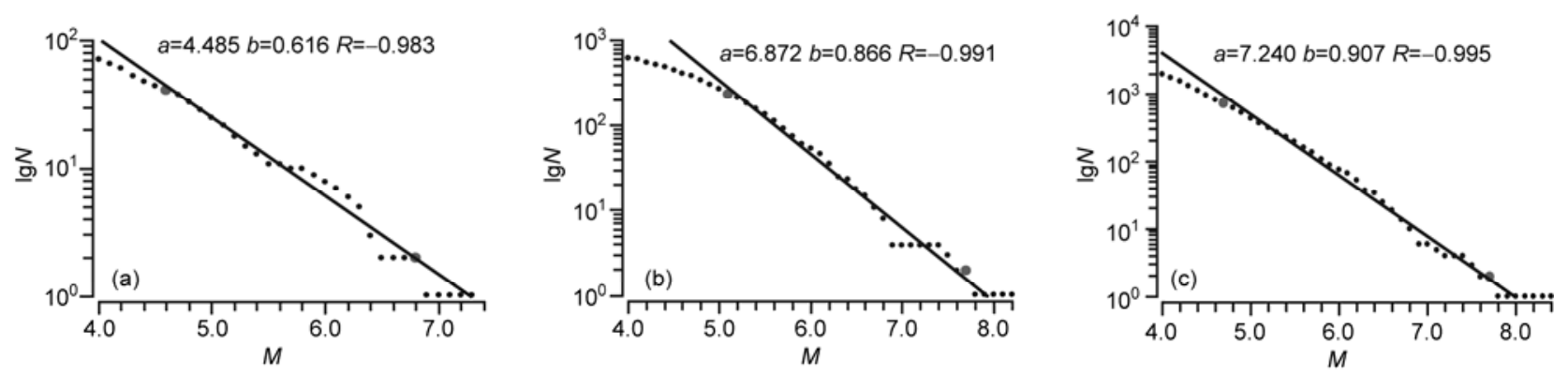

Figure 4 G-R relationships for the earthquake sequences. JMA catalog: (a) for the foreshock sequence; (b) for aftershocks in the three days after the main shock; (c) for aftershocks in the month after the main shock; $R$ is the correlation coefficient. 


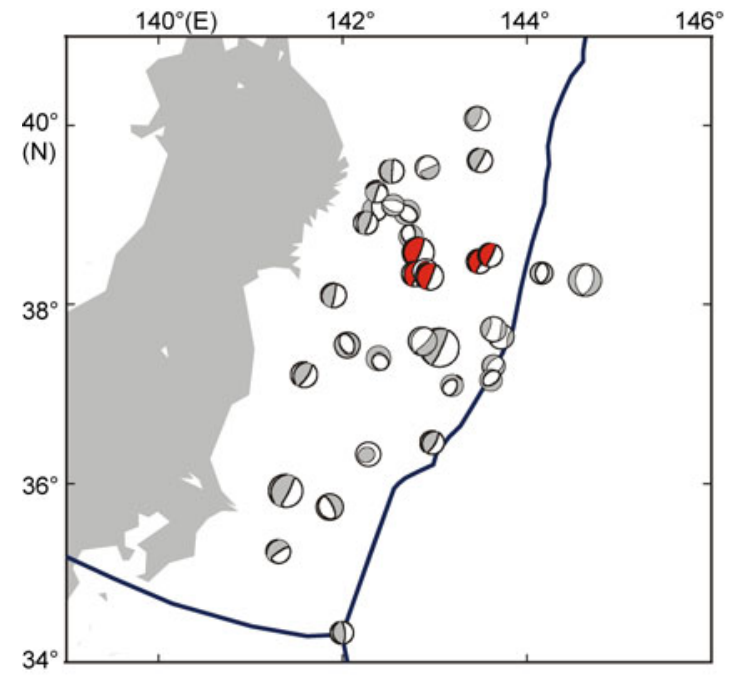

Figure 5 Sketch map of focal mechanism solution diagrams for the earthquake sequence from March 9 to 13. Red for the foreshocks and main shock; gray for aftershocks in the three days after the main shock.

annual frequency of $M \geqslant 7.0$ earthquakes of 1.1 and 0.40 , respectively. The period from 1940 to 1958 was relatively quiescent, when only one significant earthquake occurred. During the 16 years before the M9.0 earthquake (19952010), seismic activity in the area stayed at a low level. Only four shocks occurred with an average annual frequen- cy of 0.25 , significantly lower than during the active periods (Figure 6(b)).

Figure 6(a) shows the epicenter distribution of earthquakes with $M \geqslant 6.0$ from 1988 to March 2011. From 1988 to November 2001, the seismicity was weak in the vicinity of the M9.0 earthquake epicenter (the circular region in Figure 6(a)). Only eight earthquakes of $M \geqslant 6.0$ occurred (hollow circles in the circular area of Figure 6(a)). The annual frequency was 0.6 and the maximum magnitude was 6.7. From December 2001 until the 2011 M9.0 Tohoku earthquake, seismic activity significantly increased, with 32 earthquakes of $M \geqslant 6.0$ in total and an annual average frequency of 3.2, of which there were four earthquakes with $M \geqslant 7$, with the largest of those a $M 7.2$ (the solid circle in the circular area in Figure 6(a)). The March 11, 2011, M9.0 earthquake occurred right in the same location as the region of enhanced seismicity (the triangle in Figure 6(a)).

Before some great earthquakes, the activity of mid-strong magnitude earthquakes has been observed to increase. This has been described by Accelerating Moment Release [21,22] (AMR), expressed as $\sum \Omega=A+B\left(t_{f}-t\right)^{m}$, where $\Omega$ is the measure of seismicity, using the Benioff strain as in this paper; $A$ and $B$ are constants; the power exponent $m$ is called the scaling constant, and $t_{f}$ is the occurrence time of the great earthquake. When $m<1$, the release curve is accelerating; when $m>1$ the release curve is decelerating; and
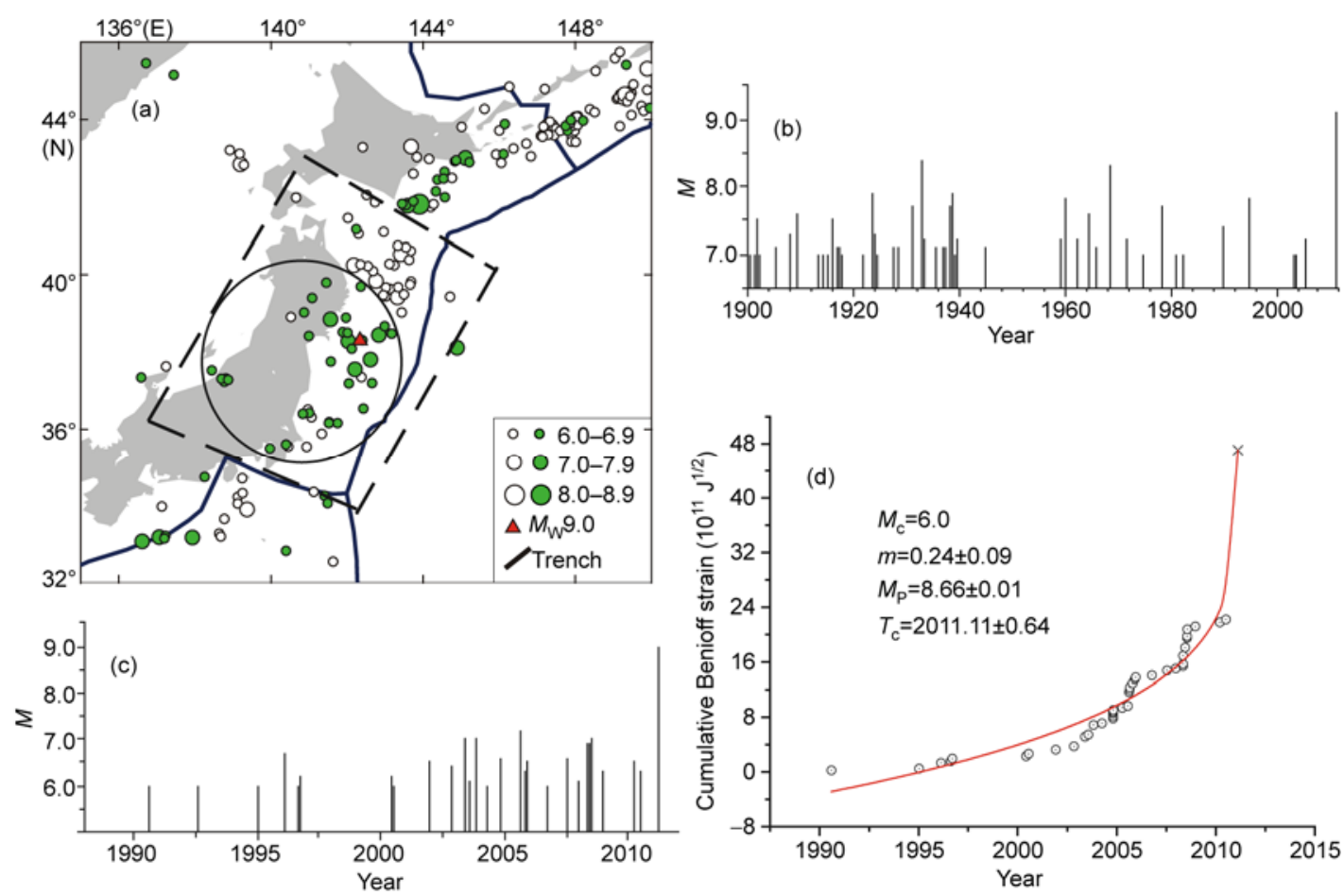

Figure 6 Seismicity in Japan Trench and the surrounding areas. (a) The epicenter distribution (light and solid circles represent the earthquakes occurring from January 1, 1988 to November 30, 2001 and December 1, 2001 to March 8, 2011; the triangle is the $M 9.0$ earthquake; (b) $M$ - $t$ chart of earthquakes with $M \geqslant 7.0$ in the Japan Trench region (the dashed rectangular area in (a)); (c) $M$ - $t$ chart of earthquakes around the $M 9.0$ source area (the circular area in (a)); (d) the cumulative Benioff strain curve fitting (the area of calculation is the circular area in (a); $M_{\mathrm{c}}$ in (d) is the calculation of the minimum magnitude, $M_{\mathrm{p}}$ is the forecast magnitude and $T_{\mathrm{c}}$ is the forecast occurrence time). 
Table 1 Statistics of global $M_{\mathrm{w}} \geqslant 8.5$ earthquakes and their $M \geqslant 7$ foreshocks since 1900

\begin{tabular}{|c|c|c|c|c|c|c|c|c|}
\hline \multicolumn{4}{|c|}{ Main shock } & \multicolumn{4}{|c|}{ Foreshock } & \multirow[b]{2}{*}{$\begin{array}{c}\text { Time interval }(\mathrm{h}) \text {; } \\
\text { epicentral } \\
\text { distance }(\mathrm{km})\end{array}$} \\
\hline $\begin{array}{l}\text { Occurrence } \\
\text { time }\end{array}$ & $\begin{array}{c}\text { Epicenter } \\
\text { latitude }\left({ }^{\circ}\right) \\
\text { longitude }\left({ }^{\circ}\right) \\
\end{array}$ & $\begin{array}{l}\text { Magnitude } \\
\qquad\left(M_{\mathrm{w}}\right)\end{array}$ & $\begin{array}{l}\text { Focal depth } \\
\qquad(\mathrm{km})\end{array}$ & $\begin{array}{c}\text { Occurrence } \\
\text { time }\end{array}$ & $\begin{array}{c}\text { Epicenter } \\
\text { latitude }\left({ }^{\circ}\right) ; \\
\text { longitude }\left(^{\circ}\right) \\
\end{array}$ & $\begin{array}{l}\text { Magnitude } \\
\qquad\left(M_{\mathrm{w}}\right)\end{array}$ & $\begin{array}{l}\text { Focal depth } \\
\quad(\mathrm{km})\end{array}$ & \\
\hline $\begin{array}{c}\text { 1922-11-11 } \\
04: 32 \\
\end{array}$ & $\begin{array}{c}-28.55 ;-70.75 \\
\text { Chile } \\
\end{array}$ & 8.7 & 35 & $\begin{array}{c}1922-11-07 \\
23: 00\end{array}$ & $-28.44 ;-72.19$ & 7.1 & 25 & $77 ; 145$ \\
\hline $\begin{array}{c}1923-02-03 \\
16: 01\end{array}$ & $\begin{array}{c}53.85 ; 160.76 \\
\text { East coast of Kamchatka }\end{array}$ & 8.5 & 35 & $\begin{array}{c}1923-02-02 \\
05: 07\end{array}$ & $54.02 ; 161.52$ & 7.1 & 35 & $34 ; 53$ \\
\hline $\begin{array}{c}1963-10-13 \\
05: 17\end{array}$ & $\begin{array}{c}44.76 ; 149.80 \\
\text { The Kurile Islands }\end{array}$ & 8.6 & 26 & $\begin{array}{c}1963-10-12 \\
11: 27\end{array}$ & $44.43 ; 149.27$ & 7.1 & 48 & $18 ; 55$ \\
\hline $\begin{array}{c}2011-03-11 \\
05: 47 \\
\end{array}$ & $\begin{array}{c}37.52 ; 143.05 \\
\text { Offshore of Honshu, Japan } \\
\end{array}$ & 9.1 & 20 & $\begin{array}{c}2001-03-09 \\
02: 45 \\
\end{array}$ & $38.58 ; 142.83$ & 7.5 & 15 & $51 ; 120$ \\
\hline
\end{tabular}

when $m=1$, the release curve is linear [23].

The seismic energy of all earthquakes with $M \geqslant 6.0$ occurring from January 1, 1988 to March 8, 2011, near the epicenter of the M9.0 event (the circular area in Figure 6(a)) was calculated using the formula of earthquake magnitude and energy proposed by Gutenberg and Richter [24]. The strain released by the earthquake was then determined by extracting the square root of the energy. The best-fit curve is $\sum \sqrt{E}=6.71 \times 10^{8}+6.84 \times 10^{8}\left(t_{f}-t\right)^{0.24}$ (Figure 6(d)). The figure shows that $m=0.24$, i.e. nine years before the $M 9.0$ earthquake, the AMR phenomenon occurred near the source region. According to the best-fit curve, this is consistent with an earthquake of M8.7 around the year 2011 (i.e. around February 12, 2011).

\section{Discussion}

Small to moderate earthquake activity before the devastating Tohoku earthquake has drawn wide attention from seismologists. In particular, the significance of identifying foreshocks for earthquake forecasts and their potential role in earthquake prediction have been an academic focus for a long time. Over the past 50 years, multiple series of obvious foreshocks occurred in China, such as those before the 1975 M7.3 Haicheng earthquake and the 1999 M5.6 Xiuyan earthquake. Statistically however, the number of moderate and strong earthquakes preceded by foreshocks is less than $10 \%$ of the total $[4,25]$. Records of strong earthquakes preceded by foreshock sequences are also very limited globally, the most notably one is the significant foreshock activity recorded before the M9.6 Chile earthquake of May 22, 1960 [17]. Statistical records show that 17 earthquakes with $M_{\mathrm{w}} \geqslant 8.5$ have occurred since 1900 globally. Five of these were preceded by a foreshock of $M \geqslant 7.0$, accounting for $29.4 \%$. This is significantly higher than the proportion of foreshocks identified before moderate or strong earthquakes. Table 1 shows the basic parameters of the five great shocks and their foreshocks. The time interval between these foreshocks and the main shocks is from several hours to four days, and the distance between foreshocks and main events is 20 to $145 \mathrm{~km}$. If the foreshock could have been identified before the occurrence of the main event, it would have been valuable for forecasting the main earthquake.

The foreshock sequence of the M9.0 earthquake along the east coast of Honshu, Japan is characterized by a concentrated spatial distribution, low $b$ value and consistent focal mechanisms. The traditional method of $h$ value determination is not an effective way to identify this particular foreshock sequence. It would be more meaningful if we were able to precisely relocate the sequence, and on that basis, make systematic analyses of the spatiotemporal evolution of the earthquake sequence [8].

Nine years prior to the $M 9.0$ earthquake, seismic activity increased markedly in the vicinity of the source region. Characteristics of regional seismic activity before great events such as this are valuable for the identification of future great earthquakes.

Our study uses the global earthquake catalog of the USGS, the catalog of this M9.0 earthquake sequence measured by Japan Meteorological Agency and GMT mapping software. Our gratitude goes to all the providers. Thanks are also extended to the peer reviewer and editor for their comments and suggestions. This work was supported by the National Basic Research Program of China (2008CB425704) and the Eleventh Five-Year National Key Technology R\&D Program (2008BAC35B05).

1 Jones L M, Molnar P. Some characteristics of foreshocks and their possible relationship to earthquake prediction and premonitory slip on fault. J Geophys Res, 1979, 84: 3596-3608

2 Wu K T. The basic types of earthquake sequences and their application in earthquake precursor (in Chinese). Earthq Front, 1971, 7: $45-51$

3 Wu K T, Yue M S, Wu H Y, et al. Certain characteristics of Haicheng earthquake ( $M=7.3$ ) sequence (in Chinese). Chin J Geophys, 1976, 19: 95-109

4 Chen Y. Consistency of focal mechanism as a new parameter in describing seismic activity (in Chinese). Chin J Geophys, 1978, 21: $140-159$ 
5 Chen Y, Liu J, Ge H K. Pattern characteristics of foreshock sequences. Pure Appl Geophys, 1999, 155: 395-408

6 Ni S D, Wang W T, Li L. The April 14th, 2010 Yushu earthquake, a devastating earthquake with foreshocks. Sci China Earth Sci, 2010, 53: 791-793

7 Suyehiro S, Asada T, Ohtake M. Foreshocks and aftershocks accompanying a perceptible earthquake in central Japan-On a peculiar nature of foreshocks. Pap Meteorol Geophys, 1964, 15: 71-88

8 Umino N, Okada T, Hasegawa A. Foreshock and aftershock sequence of the 1998 M5.0 Sendai, northeastern Japan, earthquake and its implications for earthquake nucleation. Bull Seism Soc Amer, 2002, 92: 2465-2477

9 Jiang H K, Fu Z X, Liu J, et al. Earthquake Sequences in Chinese Mainland (in Chinese). Beijing: Seismological Press, 2007. 1-175

10 Fedobov. Regularities of the distribution of strong earthquakes in Kanchatka, the Kuri Island and northeast Japan (in Russian). Tr Inst Fiz Zemli, Acad Nauk SSSR, 1965, 36: 66-93

11 Mogi K. Two kinds of seismic gaps. Pure Appl Geophys, 1979, 117: 1172-1186

12 Mei S R, Song Z P, Xue Y. Patterns and regularity of ring distribution of seismic activity before great earthquakes in China (in Chinese). Acta Seismol Sin, 1996, 18: 413-419

13 Engdahl E R, Villaseor A. Global seismicity: 1900-1999. In: Lee W H K, Kanamori H, Jennings P C, et al., eds. International Handbook of Earthquake and Engineering Seismology. San Diego: Academic Press, 2002. Part A: 665-690

14 Scholz C H. Mechanics of Earthquakes and Faulting. Cambridge:
Cambridge University Press, 2002

15 Scholz C H. Mechanisms of seismic quiescences. Pure Appl Geophys, 1988, 126: 701-718

16 Gutenberg B, Richter C F. Frequency of earthquakes in California. Bull Seism Soc Amer, 1944, 34: 185-188

17 Suyehiro S. Difference between aftershocks and foreshocks in the relationship of magnitude to frequency of occurrence for the great Chilean earthquake of 1960. Bull Seism Soc Amer, 1966, 56: 185-200

18 Omori F. On after-shocks (in Japanese). Rep Imp Earthq Inv Com, 1894, (2): 103-138

19 Omori F. On after-shocks of earthquakes. J Coll Sci Imp Univ Tokyo, 1894, (7): 111-200

20 Liu Z R. A code of practice for earthquake prediction using frequency attenuation of earthquakes (in Chinese). Earthquake, 1984, 1: 32-37

21 Main I G. Earthquakes as critical phenomena: Implications for probabilistic seismic hazard analysis. Bull Seism Soc Amer, 1995, 85: 1299-1308

22 Sornette D, Sammis C G. Critical exponents from renormalization group theory of earthquakes: Implications for earthquake prediction. J Phys I, 1995, 5: 607-619

23 Bufe C G, Varnes D J. Predictive modeling of the seismic cycle of the Greater San Francisco Bay Region. J Geophys Res, 1993, 98: 98729883

24 Gutenberg B, Richter C F. Earthquake magnitude, intensity, energy and acceleration. Bull Seism Soc Amer, 1956, 46: 105-145

25 Chen Y, Li L, Li J, et al. Wenchuan earthquake: Way of thinking is changed. Episodes, 2008, 31: 374-377

Open Access This article is distributed under the terms of the Creative Commons Attribution License which permits any use, distribution, and reproduction in any medium, provided the original author(s) and source are credited. 